\title{
Price Uncertainty and Consumer Welfare in an Intertemporal Setting
}

\author{
Shawn Ni \\ Department of Economics \\ University of Missouri-Columbia \\ NiX@missouri.edu \\ and \\ Neil Raymon \\ Department of Economics \\ University of Missouri-Columbia \\ RaymonN@missouri.edu
}

\begin{abstract}
$\underline{\text { Abstract }}$
In this paper we examine how increases in intertemporal price uncertainty affect the welfare of a consumer. In the preference structure of the consumer the coefficient of relative risk aversion and the elasticity of intertemporal substitution (EIS) are parametrically independent. We find that under empirically plausible circumstances, for each given degree of risk aversion an increase in price uncertainty reduces consumer welfare if the EIS is lower than a corresponding threshold value. Overall our results suggest that for parameter estimates found in much of the empirical literature, increases in intertemporal price uncertainty are likely to reduce consumer welfare.
\end{abstract}

JEL Classification Codes: D80, D91, E21.

Keywords: Price Uncertainty, Consumer Welfare, Risk Aversion, Intertemporal Substitution. 


\section{Introduction}

The notion that increased price uncertainty reduces consumer welfare does not always find support from economic models. In particular, analyses that focus on static settings often suggest that price uncertainty is likely to enhance consumer welfare. Waugh (1944) showed that price instability always implies higher expected consumer surplus than that implied by price stabilization. Turnovsky et al (1980) demonstrated that price instability does not always entail higher expected utility but most likely does. Baye (1985) showed that if a population of individuals has a range of preferences that includes the entire set of neoclassical preferences, then price stabilization makes at least one individual worse off. The intuition reflected in the static results cited above is that price instability brings with it both a risk (prices overall will be sufficiently high for lower utility) and an opportunity (prices overall will be sufficiently low for higher utility). Taking preferences, probabilities, and the quasi-convexity of the indirect utility function in the price vector into consideration, the opportunity may well outweigh the risk.

Situated in an intertemporal setting, the analysis of the present paper indicates that the static analysis must be supplemented. Increased price uncertainty reduces consumer welfare over a broader range of cases than the static results intuitively would suggest. The additional results in a dynamic setting derive from two, related aspects of our analysis. First, past actions are irreversible. This introduces a type of constraint on intertemporal substitution among consumption goods (i.e. on choice of the consumption vector) that has no analogue in the static setting (where the entire vector of consumption goods is chosen simultaneously).

Second is our treatment of preferences. We employ a tractable model of preferences, adopted from Weil (1990), (see also Epstein and Zin (1989)), in which risk aversion and intertemporal substitution are parametrically disentangled. Intuitively, as is discussed later in the paper, these factors play distinct roles in determining the impact of price uncertainty on consumer welfare. Hence, a choice-theoretic framework allowing separation of these factors is of interest. ${ }^{1}$

\footnotetext{
${ }^{1}$ The preference specification employed here emerges from an alternative theoretical direction in the paper of Maenhout (1999). He shows that an economic agent who has a CRRA utility function and a preference for
} 
(Compare the standard time-separable, constant relative risk aversion framework, in which the CRRA coefficient measures both the consumer's attitude toward risk and the inverse of the elasticity of intertemporal substitution.) Consideration of a more general preference structure is also supported by the empirical studies of Epstein and Zin (1991) and Giovannini and Weil (1989), in both of which the time-separable expected-utility representation is rejected.

In line with the preceding discussion, our results involve a set of pivotal conditions -conditions ensuring curvature properties of a key function in our representation of preferences -in which the degree of risk aversion and the willingness to substitute intertemporally enter independently. An example of the (generally intuitive) implications flowing from these conditions is the following. Provided that the degree of risk aversion is above a certain cutoff, for any given degree of risk aversion, the lower is a consumer's elasticity of intertemporal substitution the more likely she is to be worse off in the face of a multi-period increase in price uncertainty. We discuss this and other implications in the body of the paper. We also review some of the empirical work on risk aversion and intertemporal substitution. Overall, our results suggest that for a range of parameter values consistent with much of the empirical literature, increased price uncertainty in an intertemporal setting reduces consumer welfare.

Section 2 below presents the general model. Analysis and results are provided in Section 3, and Section 4 presents two numerical examples. Section 5 provides a brief discussion of related empirical literature. Section 6 concludes.

\section{The Model}

We consider an individual who has a finite horizon of $\mathrm{N}$ periods or an infinite horizon, who consumes one type of good, and who faces an uncertain price for that good in every period (except the first period). The consumer begins with a given level of wealth. There are no

\footnotetext{
"robustness" may behave as if she has the preference structure assumed in the present paper. Robustness is, loosely, a characteristic of the mode of decision-making in circumstances of model uncertainty such that a satisfactory outcome is attained in the worst-case scenario. For more discussion of the concept of robustness, see Anderson, Hansen, and Sargent (2000).
} 
borrowing or lending opportunities. We also assume that this individual has no productive opportunities. Thus, we are isolating the problem of price uncertainty from those of interest rate and income uncertainty.

Consistent with our earlier discussion, we assume a generalized preference structure with a constant coefficient of relative risk aversion and a constant, parametrically independent elasticity of intertemporal substitution. Following Weil (1990), the resulting recursive relationship representing this individual's preference ordering is written

$$
\begin{aligned}
& V_{k}\left(A_{k}, p_{k}\right)=\max U\left[c_{k}, E_{k} V_{k+1}\left(A_{k+1}, p_{k+1}^{*}\right)\right] \\
= & \max \frac{\left\{(1-\beta)\left(c_{k}\right)^{1-\rho}+\beta\left[1+(1-\beta)(1-\gamma) E_{k} V_{k+1}\left(A_{k+1}, p_{k+1}^{*}\right)\right]^{(1-\rho) /(1-\gamma)}\right\}^{(1-\gamma) /(1-\rho)}-1}{(1-\beta)(1-\gamma)}
\end{aligned}
$$

In (1), $A_{k}$ is wealth at the beginning of period $k$ and $p_{k}$ is the price in period $k$, (where no confusion results, the subscripts are dropped); $A_{k+1} \in\left[0, A_{k}\right]$ is wealth at the beginning of the $(\mathrm{k}+1)$ st period, optimally chosen in period $\mathrm{k}$, and $\mathrm{c}_{\mathrm{k}} \in\left[0, \mathrm{~A}_{\mathrm{k}} / \mathrm{p}_{\mathrm{k}}\right]$ is optimal consumption in the kth period, with of course $p_{k} c_{k}+A_{k+1}=A_{k}$. $V_{k}$ is the value function, mapping the period-k (wealth, price) ordered pair into expected benefit over the remaining periods. The function $U$ is an "aggregator function", (Weil (1990), p.31), the structure of which, (in (1) above), implements the generalization of the usual isoelastic preference structure with expected-utility representation. The notation "*" denotes a random variable, (this notation is sometimes dropped in the sequel; no confusion should result), $\mathrm{E}$ is the (unconditional) expectation operator, $\mathrm{E}_{\mathrm{k}}$ is the expectation conditional on $p_{k}$, and $\beta \in(0,1), \rho>0, \rho \neq 1$, and $\gamma>0, \gamma \neq 1$ are parameters. ${ }^{2}$

$\gamma$ measures relative risk aversion, (see (2) below). For deterministic time paths, $1 / \rho$ measures the elasticity of intertemporal substitution, (in (1), drop the expectation operator and by means of sequential substitution derive an expression involving successive consumption levels). 
Where time paths are random, this elasticity is not well-defined. Nonetheless, (see Hall(1988), for example), $1 / \rho$ still provides an indication of attitude toward intertemporal fluctuations per se in consumption that can constitute another source, in addition to relative risk aversion, of the adverse effect price uncertainty can have on consumer welfare in an intertemporal setting. The degree to which it represents a potential source of adverse effects on welfare is heightened under uncertainty by the fact that past actions are irreversible, a point emphasized in the introduction.

Prices are independent continuous random variables defined on the finite interval [a,b]. Initially prices are identically distributed across periods. We introduce increases in uncertainty, affecting the current and future choices of a consumer and her expected well-being, by means of mean preserving spreads of the distributions of one or more prices.

\section{3.a. Finite horizon}

We consider first the $\mathrm{N}$-period case, where $\mathrm{N} \geq 2$ and finite. By induction (the proof making use of the maximization just below), one can show that for any $\mathrm{k} \in\{1, \ldots, \mathrm{N}-1\}, \mathrm{V}_{\mathrm{k}}$ can be written

$$
\mathrm{V}_{\mathrm{k}}\left(\mathrm{A}_{\mathrm{k}}, \mathrm{p}_{\mathrm{k}}\right)=\frac{(1-\beta)^{1-\gamma / 1-\rho} A_{\mathrm{k}}^{1-\gamma} \phi_{\mathrm{k}}\left(\mathrm{p}_{\mathrm{k}}\right)-1}{(1-\beta)(1-\gamma)}
$$

where $\phi_{\mathrm{k}}\left(\mathrm{p}_{\mathrm{k}}\right)$ plays the role of a scaling function of the value of the asset, and is positive. For $\mathrm{k}$ $=\mathrm{N}$, the value function is also given by (2), with $\phi_{\mathrm{N}}$ taking the simple form $\phi_{\mathrm{N}}(\mathrm{p})=\mathrm{p}^{\gamma-1}$. Beginning with $\phi_{\mathrm{N}}$, approximate forms for the functions $\phi_{\mathrm{k}}$ can be derived sequentially, if model parameters and distributions for the prices are specified. However, here we shall be interested simply in an equation that characterizes $\phi_{\mathrm{k}}$.

\footnotetext{
${ }^{2}$ A suitable limiting treatment yields forms for the value functions for the cases of $\rho=1$ and $\gamma=1$. For simplicity we ignore these boundary cases in the development below. Results follow essentially the same pattern as that below but require changes in details because of the differing forms of the value functions.
} 
We introduce the variable $\overline{\mathrm{p}}_{\mathrm{k}}$, a function of the expectation of the scaling function $\phi_{\mathrm{k}}\left(\mathrm{p}_{\mathrm{k}}\right)$, through the definition $\overline{\mathrm{p}}_{\mathrm{k}}=\left[\mathrm{E} \phi_{\mathrm{k}}\left(\mathrm{p}_{\mathrm{k}}^{*}\right)\right]^{1-\rho / 1-\gamma}$ for $\mathrm{k} \in\{2, \ldots, \mathrm{N}\}$, where the expectation is with respect to the distribution of $\mathrm{p}_{\mathrm{k}}^{*}$. The value function $\mathrm{V}_{\mathrm{k}}$ can then be written

$$
V_{k}\left(A_{k}, p_{k}\right)=\max _{A_{k+1}} \frac{\left\{(1-\beta)\left(A_{k}-A_{k+1}\right)^{1-\rho} p_{k}^{\rho-1}+(1-\beta) \beta A_{k+1}^{1-\rho} \bar{p}_{k+1}\right\}^{1-\gamma / 1-\rho}-1}{(1-\beta)(1-\gamma)}
$$

for $\mathrm{k} \in\{1, \ldots, \mathrm{N}-1\}$. (For $\mathrm{k}=\mathrm{N}$, recall that the value function is given by (2) with $\phi_{\mathrm{N}}(\mathrm{p})=\mathrm{p}^{\gamma-1}$.) In (3), $\beta \bar{p}_{k+1}$ plays the role of a discount factor for the value of next period's initial asset level. The impact of price uncertainty is reflected in $\overline{\mathrm{p}}_{\mathrm{k}+1}$. An increase in $\overline{\mathrm{p}}_{\mathrm{k}+1}$ raises the value of the asset next period. With extraneous terms deleted, the first-order condition is

$$
-\left(\mathrm{A}_{\mathrm{k}}-\mathrm{A}_{\mathrm{k}+1}\right)^{-\rho} \mathrm{p}_{\mathrm{k}}^{\rho-1}+\beta \mathrm{A}_{\mathrm{k}+1}^{-\rho} \overline{\mathrm{p}}_{\mathrm{k}+1}=0 .
$$

It is straightforward to check that the second-order condition for a maximum holds and that in fact the (interior) solution to (4) yields a global maximum. From (4) one can derive expressions for $A_{k+1}$ and $A_{k}-A_{k+1}$. Substituting into (3) and going through some tedious but straightforward algebra, one has the following:

$$
V_{k}\left(A_{k}, p_{k}\right)=\frac{(1-\beta)^{1-\gamma / 1-\rho} A_{k}^{1-\gamma}\left\{p_{k}^{\rho-1 / \rho}+\beta^{1 / \rho} \bar{p}_{k+1}^{1 / \rho}\right\}^{\rho(1-\gamma) / 1-\rho}-1}{(1-\beta)(1-\gamma)} .
$$

Therefore we have the recursive form for the function $\phi_{\mathrm{k}}$ :

$$
\phi_{k}\left(p_{k}\right)=\left\{p_{k}^{\rho-1 / \rho}+\beta^{1 / \rho} \bar{p}_{k+1}^{1 / \rho}\right\}^{\rho(1-\gamma) / 1-\rho} \text {, where } \bar{p}_{k+1}=\left[E \phi_{k+1}\left(p^{*}\right)\right]^{1-\rho / 1-\gamma}
$$

for $\mathrm{k}=1, \ldots, \mathrm{N}-1$, (the expression for $\phi_{\mathrm{N}}\left(\mathrm{p}_{\mathrm{N}}\right)$ is given above) .

For the optimization problem specified here, the pair $\left(\mathrm{A}_{\mathrm{k}}, \mathrm{p}_{\mathrm{k}}\right)$ is given, and the prices $\mathrm{p}_{\mathrm{k}+1}$, $\ldots, \mathrm{p}_{\mathrm{N}}$ are continuous random variables, where $\mathrm{k}$ takes any value in $\{1, \ldots, \mathrm{N}-1\}$. (Hence, in all cases 
$\left(\mathrm{A}_{1}, \mathrm{p}_{1}\right)$ is nonrandom. $)$ As indicated earlier, these prices are independently distributed with finite support $[\mathrm{a}, \mathrm{b}]$ in $\mathfrak{R}_{++}$. They are taken as initially identically distributed with distribution function F. When a price has the distribution function $F$ we shall say that the price has "the initial distribution."

For any period $k=2, \ldots, N$, we use the notation " $"$ " to indicate that the value $\bar{p}_{k}=\hat{\bar{p}}_{k}$ is the value of $\bar{p}_{k}$ defined when the prices $p_{k}, \ldots, p_{N}$ are iid with the initial distribution. This same notation in the expression $\hat{\phi}_{\mathrm{k}}, \mathrm{k}=1, \ldots, \mathrm{N}$, indicates that this function is defined by (6) with $\overline{\mathrm{p}}_{\mathrm{k}+1}=\hat{\overline{\mathrm{p}}}_{\mathrm{k}+1}$.

Increases in uncertainty are introduced by means of independent mean preserving spreads (mps's) in the distributions of one or more prices, with the initial distribution maintained for the remaining prices. The mps's for different prices need not be the same. We identify three different types of increase in uncertainty. The first type is that in which there is an $m p s$ for $\mathrm{p}_{\mathrm{N}}$ only. The second type is that in which an mps occurs for some single price other than $\mathrm{p}_{\mathrm{N}}$. In the final type, the increase in uncertainty takes the form of mps's for two or more of the prices. ${ }^{3}$

We make use of the following lemmas in the sequel.

Lemma 1. For $k=2, \ldots, N-1, \overline{\mathrm{p}}_{\mathrm{k}}$ is monotonically increasing in $\overline{\mathrm{p}}_{\mathrm{k}+1}$.

Proof. The proof makes use of the definition of $\bar{p}_{k}$, the expression for $\phi_{k}$ in equation (6), and a case-by-case approach with cases defined by combinations of $\rho>1$ or $<1$ and $\gamma>1$ or $<1$. The arguments are analogous across cases, so we restrict attention to just one combination of values, $\rho<1$ and $\gamma>1$.

Using (6) and the definition of $\bar{p}_{k}$, we have

$$
\bar{p}_{k}=\left\{E\left[p_{k}^{\rho-1 / \rho}+\beta^{1 / \rho} \bar{p}_{k+1}^{1 / p}\right]^{\rho(1-\gamma) / 1-\rho}\right\}^{1-\rho / 1-\gamma}
$$


where the expectation is with respect to the distribution of $\mathrm{p}_{\mathrm{k}}$. (This distribution remains fixed when $\bar{p}_{k+1}$ changes.) Suppose that $\bar{p}_{k+1}$ increases. Then the expression in square brackets increases. Since $1-\rho>0$ and $1-\gamma<0$, the expectation decreases and $\bar{p}_{k}$ increases.//

To avoid repetition, we note here that generally applications of Lemma 1 in the sequel involve a trivial induction. The goal in each case is to show that an increase (decrease) in $\overline{\mathrm{p}}_{\mathrm{k}+\mathrm{r}}$ implies an increase (decrease) in $\bar{p}_{k+q}$ for some $r>q$.

Lemma 2. Suppose that $\mathrm{p}_{2}, \ldots, \mathrm{p}_{\mathrm{N}}$ are iid. Then for $k=2, \ldots, N-1, \overline{\mathrm{p}}_{\mathrm{k}}>\overline{\mathrm{p}}_{\mathrm{k}+1}$.

Proof. The proof is by induction. (Implicitly, the proof here covers the four cases defined in the proof of Lemma 1.) Consider first $\mathrm{k}=\mathrm{N}-1$. Using the definition of $\overline{\mathrm{p}}_{\mathrm{N}-1}$ and $\overline{\mathrm{p}}_{\mathrm{N}}$ in terms of $\phi_{\mathrm{N}-1}$ and $\phi_{N}$, respectively, and making use of equation (7), we obtain

$$
\begin{aligned}
\overline{\mathrm{p}}_{\mathrm{N}-1}= & \left\{\mathrm{E}\left[\mathrm{p}_{\mathrm{N}-1}^{\rho-1 / \rho}+\beta^{1 / \rho} \overline{\mathrm{p}}_{\mathrm{N}}^{1 / \rho}\right]^{\rho(1-\gamma) / 1-\rho}\right\}^{1-\rho / 1-\gamma} \\
& >\left\{\mathrm{E}\left[\mathrm{p}_{\mathrm{N}}^{\rho-1 / \rho}\right]^{\rho(1-\gamma) / 1-\rho}\right\}^{1-\rho / 1-\gamma}=\left\{\mathrm{Ep}_{\mathrm{N}}^{\gamma-1}\right\}^{1-\rho / 1-\gamma}=\overline{\mathrm{p}}_{\mathrm{N}} .
\end{aligned}
$$

Note that in the term after the inequality, we have substituted $\mathrm{p}_{\mathrm{N}}$ for $\mathrm{p}_{\mathrm{N}-1}$. Only the notation differs here; the two variables both represent the iid price random variable that is assumed in the present lemma.

\footnotetext{
${ }^{3}$ We could articulate this taxonomy so that the three types of increase in uncertainty are nested. The way in which we have chosen to distinguish the types simplifies the formal exposition.
} 
Turning now to the general case, for purposes of the formal proof, switch to subscript $\mathrm{j}, \mathrm{j}$ $=4, \ldots, N$, and suppose that $\overline{\mathrm{p}}_{\mathrm{j}-1}>\overline{\mathrm{p}}_{\mathrm{j}}$. Then we need to show that $\overline{\mathrm{p}}_{\mathrm{j}-2}>\overline{\mathrm{p}}_{\mathrm{j}-1}$. The proof is simply the following:

$$
\begin{aligned}
\bar{p}_{j-2}= & \left\{E\left[p_{j-2}^{\rho-1 / \rho}+\beta^{1 / \rho} \bar{p}_{j-1}^{1 / \rho}\right]^{\rho(1-\gamma) / 1-\rho}\right\}^{1-\rho / 1-\gamma} \\
& >\left\{E\left[p_{j-1}^{\rho-1 / \rho}+\beta^{1 / \rho} \bar{p}_{j}^{1 / \rho}\right]^{\rho(1-\gamma) / 1-\rho}\right\}^{1-\rho / 1-\gamma}=\bar{p}_{j-1} \cdot / /
\end{aligned}
$$

That the sequence of the $\bar{p}_{k}$ is decreasing is consistent with our interpretation of $\beta \bar{p}_{k}$ as the discount scalar for the value of the initial asset level in period $\mathrm{k}$. In period $\mathrm{k}$ there is one more period left compared with period $\mathrm{k}+1$. Hence the discount factor for asset-holding at the outset of period $\mathrm{k}$ is larger than its counterpart for period $\mathrm{k}+1, \beta \overline{\mathrm{p}}_{\mathrm{k}+1}$.

For an increase in price uncertainty in the last period of life we have the following result.

Proposition 1. Suppose that there is an mps for $p_{N}$. Then for any given $\mathrm{k} \in\{1, \ldots, \mathrm{N}-1\}$ and corresponding realization $\left(A_{k}, p_{k}\right)$ :

(a) If $\gamma<2, V_{k}\left(A_{k}, p_{k}\right)$ increases.

(b) If $\gamma=2, V_{k}\left(A_{k}, p_{k}\right)$ is unchanged.

(c) If $\gamma>2, V_{k}\left(A_{k}, p_{k}\right)$ decreases.

Proof. The cases (a)-(c) are broken down into subcases according to the specified range of values for $\rho$. Demonstrations for all subcases are very similar, so we restrict attention to $\gamma>2$ and $\rho<1$

From $\gamma>2, \mathrm{p}_{\mathrm{N}}^{\gamma-1}$ is strictly convex, so that an mps implies that $\mathrm{E}_{\mathrm{N}}^{\gamma-1}$ increases. ${ }^{4}$ This, together with $(1-\rho) /(1-\gamma)<0$, implies that $\overline{\mathrm{p}}_{\mathrm{N}}$ decreases. Using Lemma 1 , it is then easy to see

\footnotetext{
${ }^{4}$ That the expectation of a strictly convex (strictly concave) function increases (decreases) with an mps follows from the equivalence results in the paper by Rothschild and Stiglitz (1970).
} 
that $\bar{p}_{\mathrm{k}}$ decreases for all $\mathrm{k}$. This and $(1-\gamma) /(1-\rho)<0$ imply that the numerator in (5) increases for any $k$. Since $1-\gamma<0, \mathrm{~V}_{\mathrm{k}}\left(\mathrm{A}_{\mathrm{k}}, \mathrm{p}_{\mathrm{k}}\right)$ decreases.//

By way of expansion on the statement of results in Proposition 1, suppose that there is an mps in period $N$. Then if the consumer finds herself in some period $k \in\{1, \ldots, N-1\}$, with some realization $\left(A_{k}, p_{k}\right)$, she is unaffected by the increase in uncertainty if $\gamma=2$; she is better off (worse off) than she would have been in that period, with that realization, if $\gamma<2(\gamma>2)$.

Intuitively, this result can be understood by noting that the agent consumes everything in the last period of life regardless of the last period price. When the price in the last period of life is observed the agent cannot reverse the decision she made in the previous period and there are no future periods for which to plan. For this reason the welfare effect of price uncertainty only depends on the risk aversion parameter. The elasticity of intertemporal substitution plays no role.

We focus briefly on the different effect of price instability in a static multi-good setting as opposed to a dynamic multi-period setting. In both the multi-good and multi-period models, price instability creates opportunity but also risk for consumers. Under certain circumstances the benefit of the opportunity outweighs the risk. Intuitively price instability in a static multi-good model tends to be more favorable to consumers than that in a comparable multi-period model. This is because in the static multi-good model, consumption for all goods is decided after the realization of prices, whereas in a multi-period model, consumption of some goods is chosen before the realization of uncertain future prices. In comparison, different goods are better intratemporal substitutes in the static setting than they are intertemporal substitutes in the dynamic setting, and the demands for the goods with uncertain prices are more elastic in the static multi-good setting. We can support this intuition by comparing the following two-good model with the two-period model. In the two-good model, the price of good one is fixed at 1 ; the price of good $2, \mathrm{p}$, is uncertain. Consumption decisions for both goods are made after $\mathrm{p}$ is observed. 
Suppose the utility function is of the constant relative risk aversion type. The consumer's indirect utility function, (defined in terms of the relative price $p$ ), is $W(A, p)=\max$ $\left(\mathrm{c}_{1}^{1-\gamma}-1\right) /(1-\gamma)+\beta\left(\mathrm{c}_{2}^{1-\gamma}-1\right) /(1-\gamma)$, where the budget constraint is $\mathrm{c}_{1}+\mathrm{pc}_{2}=\mathrm{A}$. We are interested in the condition under which the second order partial derivative with respect to price is greater than 0 . One can easily verify that $\partial^{2} \mathrm{~W} / \partial \mathrm{p}^{2}>0$ at the mean price $\mathrm{p}=1$ if and only if $\gamma(\gamma-2)<\beta^{-1 / \gamma}$. If $\beta=1$ then the threshold level such that the consumer benefits (suffers) from the instability in $\mathrm{p}$ is defined by $\gamma$ smaller (larger) than 2.414 . If $\beta<1$ then the threshold is even larger. Recall that Proposition 1 states that in a corresponding two-period model, when $\gamma=2$ the consumer is indifferent to instability in the second period price. This example suggests that price instability in multi-period settings is less favorable than price instability in static multi-good settings.

The size of $\gamma$ in relation to the benchmark value of 2 and the curvature of $\phi_{\mathrm{N}}(\mathrm{p})=\mathrm{p}^{\gamma-1}$ are key elements in the statement and proof of Proposition 1. When we turn to the two other types of increase in uncertainty, the situation is similar. Here is the main result for the case of an mps for a single price other than $\mathrm{p}_{\mathrm{N}}$.

Consider the function

$$
\xi_{\mathrm{k}+1}(\mathrm{p})=\rho(\gamma-2)-\beta^{1 / \rho} \hat{\bar{p}}_{\mathrm{k}+2}^{1 / \rho} \mathrm{p}^{1-\rho / \rho}
$$

Proposition 2 shows that the sign of the function $\xi_{\mathrm{k}+1}$ determines the welfare effect of an mps for $\mathrm{p}_{\mathrm{k}+1}^{*}$ for some single $\mathrm{k} \in\{1, \ldots, \mathrm{N}-2\}$.

Proposition 2. If $\xi_{\mathrm{k}+1}(\mathrm{p})<0$ on $(a, b)$, then for any $j=1, \ldots, k$ and corresponding realization $\left(A_{j}, p_{j}\right), V_{j}\left(A_{j}, p_{j}\right)$ increases. If $\xi_{\mathrm{k}+1}(\mathrm{p})>0$ on $(a, b)$, then for any such $j, V_{j}\left(A_{j}, p_{j}\right)$ decreases.

Proof. Begin with $\phi_{\mathrm{k}+1}\left(\mathrm{p}_{\mathrm{k}+1}\right)$ defined as in (6). The second derivative with respect to $\mathrm{p}_{\mathrm{k}+1}$ is 


$$
\begin{gathered}
\phi_{\mathrm{k}+1}^{\prime \prime}\left(\mathrm{p}_{\mathrm{k}+1}\right)=[\rho(1-\gamma) /(1-\rho)][\rho(1-\gamma) /(1-\rho)-1]\left\{\mathrm{p}_{\mathrm{k}+1}^{\rho-1 / \rho}+\beta^{1 / \rho} \overline{\mathrm{p}}_{\mathrm{k}+2}^{1 / \rho}\right\}^{\frac{\rho(1-\gamma)}{1-\rho}-2}[(\rho-1) / \rho]^{2} \mathrm{p}_{\mathrm{k}+1}^{-2 / \rho} \\
+[\rho(1-\gamma) /(1-\rho)]\left\{\mathrm{p}_{\mathrm{k}+1}^{\rho-1 / \rho}+\beta^{1 / \rho} \overline{\mathrm{p}}_{\mathrm{k}+2}^{1 / \rho}\right\}^{\frac{\rho(1-\gamma)}{1-\rho}-1}[(\rho-1) / \rho](-1 / \rho) \mathrm{p}_{\mathrm{k}+1}^{\frac{-1}{\rho}-1}
\end{gathered}
$$

This expression is $<0(>0)$ on $(a, b)$ as

$$
(\gamma-1)[\rho(1-\gamma) /(1-\rho)-1][(\rho-1) / \rho]+(\gamma-1)(-1 / \rho)\left\{\mathrm{p}_{\mathrm{k}+1}^{\rho-1 / \rho}+\beta^{1 / \rho} \overline{\mathrm{p}}_{\mathrm{k}+2}^{1 / \rho}\right\} \mathrm{p}_{\mathrm{k}+1}^{1-\rho / \rho}<0(>0) \text { on }(\mathrm{a}, \mathrm{b}) .
$$

We have, after some further manipulation, that this is equivalent to $(\gamma-1) \xi_{\mathrm{k}+1}\left(\mathrm{p}_{\mathrm{k}+1}\right)<0$ (>0) on $(\mathrm{a}, \mathrm{b})$. It follows that $\phi_{\mathrm{k}+1}\left(\mathrm{p}_{\mathrm{k}+1}\right)$ is strictly concave (strictly convex) on [a,b] as $(\gamma-1) \xi_{\mathrm{k}+1}\left(\mathrm{p}_{\mathrm{k}+1}\right)<0(>0)$ on $(\mathrm{a}, \mathrm{b})$. From the recursive structure in the current setting, it follows that the mps for $\mathrm{p}_{\mathrm{k}+1}^{*}$ does not affect $\overline{\mathrm{p}}_{\mathrm{k}+2}$. Hence, $\overline{\mathrm{p}}_{\mathrm{k}+2}=\hat{\overline{\mathrm{p}}}_{\mathrm{k}+2}$ in the definition of $\xi_{\mathrm{k}+1}$, and also $\phi_{\mathrm{k}+1}$ is the function $\hat{\phi}_{\mathrm{k}+1}$.

As with Proposition 1, there are a number of subcases. Here, the subcases are defined by the size of $\gamma$, the size of $\rho$, and the sign of $\xi_{\mathrm{k}+1}\left(\mathrm{p}_{\mathrm{k}+1}\right)$ on $(\mathrm{a}, \mathrm{b})$. Again, as with Proposition 1 , demonstrations for the various subcases are similar. We therefore restrict attention to a single subcase. We take $\gamma>2, \rho<1$, and $\xi_{\mathrm{k}+1}\left(\mathrm{p}_{\mathrm{k}+1}\right)>0$, (for which $\gamma>2$ is a necessary condition).

For this subcase, $\hat{\phi}_{\mathrm{k}+1}\left(\mathrm{p}_{\mathrm{k}+1}\right)$ is strictly convex in $\mathrm{p}_{\mathrm{k}+1}$. Then $\mathrm{E} \hat{\phi}_{\mathrm{k}+1}\left(\mathrm{p}_{\mathrm{k}+1}^{*}\right)$ increases with the mps for $\mathrm{p}_{\mathrm{k}+1}^{*}$. With $(1-\rho) /(1-\gamma)<0$, it follows that $\overline{\mathrm{p}}_{\mathrm{k}+1}$ falls with the mps. Consequently, from (6), for any given $p_{k}, \phi_{k}\left(p_{k}\right)$ increases since $(1-\gamma) /(1-\rho)<0$. Finally, the fact that $1-\gamma<0$ implies that for any realization $\left(A_{k}, p_{k}\right), V_{k}\left(A_{k}, p_{k}\right)$ decreases with the mps.

If $\mathrm{k}>1$, take any $\mathrm{j}=1, \ldots, \mathrm{k}-1$. Since $\overline{\mathrm{p}}_{\mathrm{k}+1}$ decreases, Lemma 1 implies that $\overline{\mathrm{p}}_{\mathrm{j}+1}$ falls for any j. (Note that the random variables $p_{j+1}^{*}, j=1, \ldots, k-1$, remain iid with the initial distribution.) Then as above, for any given $\mathrm{p}_{\mathrm{j}}, \phi_{\mathrm{j}}\left(\mathrm{p}_{\mathrm{j}}\right)$ increases, and for any realization $\left(\mathrm{A}_{\mathrm{j}}, \mathrm{p}_{\mathrm{j}}\right), \mathrm{V}_{\mathrm{j}}\left(\mathrm{A}_{\mathrm{j}}, \mathrm{p}_{\mathrm{j}}\right)$ decreases with the mps.// 
The intuition for this result dovetails with that for Proposition 1. As is noted earlier in the discussion following Proposition 1, when there is an increase in price uncertainty in the last period, the agent is unable to change consumption decisions made in the past and there are no future periods, so the elasticity of intertemporal substitution (EIS) does not affect the condition under which the increase in price uncertainty increases or reduces consumer welfare. Alternatively, consider the effect of a one-time increase in price uncertainty in period $k+1$ when there are one or more periods left in the agent's life. The agent can make changes in (ex ante plans for) future consumption after observing the price for period $k+1$. The welfare implication of this option depends on the EIS. The role of the EIS depends on the number of periods the agent has left after the increase in price uncertainty is resolved.

From Proposition 2, an increase in uncertainty in the period $\mathrm{k}+1$ price makes the consumer worse off if $\rho(\gamma-2)>\beta^{1 / \rho} \hat{\bar{p}}_{k+2}^{1 / \rho} p^{1-\rho / \rho}$ for $p \in(a, b)$ and better off with the reverse inequality. Note that under the condition $\gamma=2$, which according to Proposition 1 makes the consumer indifferent to price uncertainty in the last period, the consumer's welfare is increased when there are more periods left in her life after the realization of increased price uncertainty.

More generally, the inequality above suggests the question: How do the coefficient of risk aversion $\gamma$ and EIS $1 / \rho$ determine the welfare effect of an increase in price uncertainty? Intuitively, increased price uncertainty should be welfare reducing if the consumer is risk averse ( $\gamma$ is large) or reluctant to substitute consumption intertemporally ( $\rho$ is large). So for a larger $\gamma$ the threshold value of $\rho$, (that is, the value at which $\xi_{\mathrm{k}+1}(\mathrm{p})=0$ holds for some $\mathrm{p}$ and beyond which $\xi_{\mathrm{k}+1}(\mathrm{p})>0$ on $\left.(\mathrm{a}, \mathrm{b})\right)$, should be smaller. It turns out that this intuition is not always correct. To see why, let $\gamma$ be fixed at a value above 2 , and the current price $\mathrm{p}$ be set at 1 . There are two scenarios to be considered.

If $\beta \hat{\overline{\mathrm{p}}}_{\mathrm{k}+2} \geq 1$, then as $\rho$ becomes larger the inequality is more likely to hold. This supports the intuition in the preceding paragraph: when the EIS $(1 / \rho)$ is smaller the consumer is more likely to be hurt by increased price uncertainty. Another useful insight the above inequality reveals 
is the following. According to Lemma 2, $\overline{\mathrm{p}}_{\mathrm{k}}$ is decreasing in $\mathrm{k}$. Therefore if $\mathrm{k}$ is larger (that is, when the increase in price uncertainty occurs later) the inequality is more likely to hold, i.e., the consumer is more likely to be hurt by increased price uncertainty. This is because when there are fewer periods left in the consumer's life after the (now increased) price uncertainty is resolved the consumer's ability to respond is more limited. A practical implication is that in an economy with agents of different ages, old agents' welfare is more likely to be adversely affected by price uncertainty than that of young agents.

Because $\hat{\bar{p}}_{k+2}$ is decreasing in $\mathrm{k}$, the greater the number of periods that remain after an increase in uncertainty, the more likely it is that $\beta \hat{\bar{p}}_{k+2} \geq 1$ holds, implying that increases in $\rho$ make it more likely that the consumer is worse off, in accord with intuition. On the other hand, more periods remaining after the increase in uncertainty implies that for a given $\rho$, it is more likely that the consumer is better off ( $\beta \hat{\overline{\mathrm{p}}}_{\mathrm{k}+2}$ is larger), again in accord with intuition.

The alternative case is that of $\beta \hat{\bar{p}}_{k+2}<1$. There are two possible subcases. If $\rho$ is large, then the sign of the function $\xi_{\mathrm{k}+1}$ is mainly determined by the size of the term $\rho(\gamma-2)$. The larger is the value of $\gamma$, the smaller is the threshold value of $\rho$. The role of $\rho$ and that of the size of $k$ are the same in this subcase as in the case discussed above.

On other hand if $\rho$ is small then the sign of $\xi_{k+1}$ is determined by how close $\rho$ is to 0 . This is because as $\rho \rightarrow 0,\left(\beta \hat{\bar{p}}_{k+2}\right)^{1 / \rho}$ converges to 0 faster than $\rho$ does. ${ }^{5}$ It follows that $\xi_{k+1}(p)$ is positive when $\rho$ is sufficiently small, i.e., for a given value of the risk aversion parameter, an increase in price uncertainty is more likely to make the consumer worse off when she has a larger EIS. This implication is counter-intuitive. Because one would expect that with a larger EIS there is more flexibility in allocating consumption intertemporally, the opportunity aspect of fluctuations in prices should offer higher benefit and the consumer should be more likely to be made better off

\footnotetext{
5 This statement holds true taking into account the fact that $\hat{\bar{p}}_{k+2}$ also depends on $\rho$.
} 
by increased price uncertainty. The apparent puzzle can be explained when we analyze more closely the benefit of price fluctuations in this case. When the EIS is large and the parameter $\beta$ is small, the consumer finds it is optimal to consume early. Imagine that it is optimal to consume most of her resources in the first period of life, before realization of any price uncertainty. The "front loading" of the consumption profile means that after the realization of price uncertainty there is not much wealth left to consume. When the uncertain price turns out to be low the consumer's gain is limited by her lack of resources. When the consumer consumes her resources early due to a low $\beta$ together with an already large EIS, a larger EIS (i.e., smaller $\rho$ ) leads to further front-loading. This effect can offset the benefit of intertemporal flexibility and result in a net reduction in welfare. In Section 4, we further illustrate this explanation with a numerical example. The example also suggests that the first, more intuitive subcase is the one consistent with conventional estimates of the EIS.

We have a corollary to Proposition 2. Consider the following conditions:

and

$$
\begin{aligned}
& \rho(\gamma-2)<\beta^{1 / \rho} \hat{\bar{p}}_{N}^{1 / a^{1-\rho} / p} \text { for } \rho<1 \\
& \rho(\gamma-2)<\beta^{1 / \rho} \hat{\bar{p}}_{N}^{1 / p} b^{1-\rho / p} \text { for } \rho>1,
\end{aligned}
$$

$$
\begin{aligned}
& \rho(\gamma-2)>\beta^{1 / \rho} \hat{\bar{p}}_{2}^{1 / p} b^{1-\rho / \rho} \text { for } \rho<1 \\
& \rho(\gamma-2)>\beta^{1 / \rho} \hat{\bar{p}}_{2}^{1 / \rho_{a}}{ }^{1-\rho / \rho} \text { for } \rho>1 .
\end{aligned}
$$

Corollary. Suppose that there is an mps for a price $\mathrm{p}_{\mathrm{k}+1}^{*}$, for some single $\mathrm{k} \in\{1, \ldots, \mathrm{N}-2\}$. Then for any $j=1, \ldots, k$, and corresponding realization $\left(\mathrm{A}_{\mathrm{j}}, \mathrm{p}_{\mathrm{j}}\right), \mathrm{V}_{\mathrm{j}}\left(\mathrm{A}_{\mathrm{j}}, \mathrm{p}_{\mathrm{j}}\right)$ increases if (9) holds, decreases if (10) holds.

Proof. From Lemma 2, $\hat{\bar{p}}_{\mathrm{N}} \leq \hat{\overline{\mathrm{p}}}_{\mathrm{k}+2}<\hat{\overline{\mathrm{p}}}_{2}$. It follows that condition (9) implies $\xi_{\mathrm{k}+1}(\mathrm{p})<0$ for $\mathrm{p}=$ a, (if $\rho<1$ ), and for $\mathrm{p}=\mathrm{b}$, (if $\rho>1$ ). Similarly, condition (10) implies $\xi_{\mathrm{k}+1}(\mathrm{p})>0$ for $\mathrm{p}=\mathrm{b}$, (if 
$\rho<1$ ), and for $\mathrm{p}=\mathrm{a}$, (if $\rho>1$ ). Because all values of $\mathrm{p}$ lie in $[\mathrm{a}, \mathrm{b}]$, this means that $\xi_{\mathrm{k}+1}(\mathrm{p})<0$ on [a,b] if condition (9) holds and $\xi_{\mathrm{k}+1}(\mathrm{p})>0$ on $[\mathrm{a}, \mathrm{b}]$ if condition (10) holds. The results for $\mathrm{V}_{\mathrm{j}}$ then follow from Proposition 2.//

Conditions (9) and (10) are more restrictive than analogous conditions involving the function $\xi_{\mathrm{k}+1}$ defined in (8). The main significance of the corollary is that the conditions (9) and (10) are independent of the timing, in addition to the other characteristics, of the particular mps being considered.

Suppose now the third type of increase in uncertainty: independent mps's for two or more prices. Let $\mathrm{h}+1$ denote the earliest period in which there is an $\mathrm{mps}$, for $\mathrm{p}_{\mathrm{h}+1}^{*}$, where $\mathrm{h}$ takes some value in $\{1, \ldots, \mathrm{N}-2\}$. If the mps for $\mathrm{p}_{\mathrm{h}+1}^{*}$ were the only mps, then we would be in the context of Proposition 2. In that context, the post-mps value of $\overline{\mathrm{p}}_{\mathrm{h}+2}$ is $\hat{\overline{\mathrm{p}}}_{\mathrm{h}+2}$ and the post-mps function $\phi_{\mathrm{h}+1}$ is $\hat{\phi}_{\mathrm{h}+1}$. This configuration reflects the fact that there is no increase in uncertainty beyond that in period $\mathrm{h}+1$.

In the current context, the post-mps value of $\overline{\mathrm{p}}_{\mathrm{h}+2}$, denote it $\overline{\mathrm{p}}_{\mathrm{h}+2}^{\mathrm{r}}$, is not equal to $\hat{\overline{\mathrm{p}}}_{\mathrm{h}+2}$. (In the present discussion and in Proposition 3, the superscript " $r$ " denotes post-mps values and functions.) This is because there is at least one period $\mathrm{k} \geq \mathrm{h}+2$ in which there is an mps for $\mathrm{p}_{\mathrm{k}}^{*}$. That is, $\overline{\mathrm{p}}_{\mathrm{h}+2}^{\mathrm{r}}$ differs from the initial value $\hat{\overline{\mathrm{p}}}_{\mathrm{h}+2}$ because of a change directly in the distribution of $\mathrm{p}_{\mathrm{h}+2}^{*}$ due to an mps and/or because there is an mps for some $\mathrm{k}>\mathrm{h}+2$, the latter then affecting the value of $\bar{p}_{h+2}$ through the recursive relation (7), (or equivalently, through recursive application of the definition of $\overline{\mathrm{p}}_{\mathrm{k}}$ with $\phi_{\mathrm{k}}$ determined in (6), $\mathrm{k} \geq \mathrm{h}+2$ ). The value $\overline{\mathrm{p}}_{\mathrm{h}+2}=\overline{\mathrm{p}}_{\mathrm{h}+2}^{\mathrm{r}}$, and hence also the post-mps function $\phi_{\mathrm{h}+1}=\phi_{\mathrm{h}+1}^{\mathrm{r}}$, thus depend on the entire set of mps's other than that for $\mathrm{p}_{\mathrm{h}+1}^{*}$. They reflect that part of the increase in uncertainty represented by the set of mps's for periods $\mathrm{k} \geq \mathrm{h}+2$. The dichotomy here between the increase in uncertainty in period $\mathrm{h}+1$ and that in some periods $\mathrm{k}$ later than $\mathrm{h}+1$ arises because period $\mathrm{h}+1$ marks the boundary between periods where 
there is no increase in uncertainty $(\mathrm{k}=1, \ldots, \mathrm{h})$ and periods in some of which an increase in uncertainty occurs (the boundary period $h+1$ and some of the periods $k \geq h+2$ ).

In light of the dichotomy just noted, a similarity here to the case of a single mps is the pivotal role played by $\phi_{\mathrm{h}+1}^{\mathrm{r}}$, with the additional element now of how this function is related to $\hat{\phi}_{\mathrm{h}+1}$. The curvature of $\hat{\phi}_{\mathrm{h}+1}$ is still important and so the function $\xi_{\mathrm{h}+1}$ (p) defined in (8), (with the subscript $\mathrm{h}$ replacing $\mathrm{k}$ ), is important. We have the following result.

Proposition 3. Suppose that there is a set of independent mps's, not necessarily the same, for two or more prices $\mathrm{p}_{\mathrm{k}+1}^{*}$, where $\mathrm{k} \in\{1, \ldots, \mathrm{N}-1\}$. Let $h+1$ denote the earliest period in which there is an mps, and $h+M$ the last period in which there is an mps, where $h$ takes some value in $\{1, \ldots, N-2\}, M$ some value in $\{2, \ldots, N-h\}$. If $\xi_{\mathrm{h}+1}(\mathrm{p})>0$ on $(a, b)$, then for any $j=1, \ldots, h+M-1$ $\mathrm{V}_{\mathrm{j}}^{\mathrm{r}}(\mathrm{A}, \mathrm{p})<\mathrm{V}_{\mathrm{j}}(\mathrm{A}, \mathrm{p})$ for any $A>0$ and $\mathrm{p} \in[\mathrm{a}, \mathrm{b}]$ (here, $\mathrm{V}_{\mathrm{j}}$ is the initial, pre-mps value function for period $j)$. That is, for any such $j$ and corresponding realization $\left(\mathrm{A}_{\mathrm{j}}, \mathrm{p}_{\mathrm{j}}\right)$, the consumer is worse off.

Proof. The proofs for the cases of $\rho<1$ and $\rho>1$ are very similar, so we present in detail only the proof for $\rho<1$.

The strategy of the proof is this. First we show that $\overline{\mathrm{p}}_{\mathrm{h}+\mathrm{k}}^{\mathrm{r}}<\hat{\overline{\mathrm{p}}}_{\mathrm{h}+\mathrm{k}}$ for $\mathrm{k}=1, \ldots, \mathrm{M}$. Then we use $\overline{\mathrm{p}}_{\mathrm{h}+1}^{\mathrm{r}}<\hat{\overline{\mathrm{p}}}_{\mathrm{h}+1}$ to show that $\overline{\mathrm{p}}_{\mathrm{j}}^{\mathrm{r}}<\hat{\overline{\mathrm{p}}}_{\mathrm{j}}$ for $\mathrm{j}=2, \ldots, \mathrm{h}$. Finally, from these results we obtain the desired conclusion regarding the value functions. It should perhaps be noted that there is some redundancy of implications in the proof, but we proceed as we do for the sake of a unified logical pattern.

We show by induction that $\overline{\mathrm{p}}_{\mathrm{h}+\mathrm{k}}^{\mathrm{r}}<\hat{\overline{\mathrm{p}}}_{\mathrm{h}+\mathrm{k}}$ on the set $\mathrm{K}=\{1, \ldots, \mathrm{M}\}$, (note that for some elements $\mathrm{k} \in \mathrm{K}$, there may not be an mps for $\mathrm{p}_{\mathrm{h}+\mathrm{k}}^{*}$ ). If $\mathrm{M}=\mathrm{N}-\mathrm{h}$, so that $\mathrm{p}_{\mathrm{h}+\mathrm{M}}^{*}=\mathrm{p}_{\mathrm{N}}^{*}$, then the strict convexity of $\hat{\phi}_{\mathrm{N}}$, (implied by $\gamma>2$, which is in turn implied by $\xi_{\mathrm{h}+1}(\mathrm{p})>0$ ), along with $\rho<1$ 
and $\gamma>2$, imply that the mps for $\mathrm{p}_{\mathrm{N}}^{*}$ leads to $\overline{\mathrm{p}}_{\mathrm{h}+\mathrm{M}}^{\mathrm{r}}=\overline{\mathrm{p}}_{\mathrm{N}}^{\mathrm{r}}<\hat{\overline{\mathrm{p}}}_{\mathrm{N}}=\hat{\overline{\mathrm{p}}}_{\mathrm{h}+\mathrm{M}}$. Alternatively, suppose that $\mathrm{M}<\mathrm{N}-\mathrm{h}$. Then using the definition of $\mathrm{M}$ and, as in Proposition 2, the recursive structure in the current setting, we have $\overline{\mathrm{p}}_{\mathrm{h}+\mathrm{M}+1}^{\mathrm{r}}=\hat{\overline{\mathrm{p}}}_{\mathrm{h}+\mathrm{M}+1}$. From (6), this implies $\phi_{\mathrm{h}+\mathrm{M}}^{\mathrm{r}}=\hat{\phi}_{\mathrm{h}+\mathrm{M}}$. Also, from Lemma 2, $\hat{\overline{\mathrm{p}}}_{\mathrm{h}+\mathrm{M}+1}<\hat{\overline{\mathrm{p}}}_{\mathrm{h}+2}$. Since $\xi_{\mathrm{h}+1}(\mathrm{p})>0$ on $(\mathrm{a}, \mathrm{b})$, it follows that $\xi_{\mathrm{h}+\mathrm{M}}(\mathrm{p})>0$ on $(\mathrm{a}, \mathrm{b})$. Thus, just as in Proposition $2, \hat{\phi}_{\mathrm{h}+\mathrm{M}}$ is strictly convex on $[\mathrm{a}, \mathrm{b}]$. Consequently, using $(1-\rho) /(1-\gamma)<0$, the mps for $\mathrm{p}_{\mathrm{h}+\mathrm{M}}^{*}$ leads to -

Suppose now that $-\ldots \quad-\quad$ for $\quad$, for some $m$ satisfying

Then we want to show that $\overline{\mathrm{p}}_{\mathrm{h}+\mathrm{m}-1}^{\mathrm{r}}<\hat{\overline{\mathrm{p}}}_{\mathrm{h}+\mathrm{m}-1}$. We know that $\overline{\mathrm{p}}_{\mathrm{h}+\mathrm{m}}^{\mathrm{r}}<\hat{\overline{\mathrm{p}}}_{\mathrm{h}+\mathrm{m}}$, implying, (using (6) and $(1-\gamma) /(1-\rho)<0)$, that $\phi_{\mathrm{h}+\mathrm{m}-1}^{\mathrm{r}}(\mathrm{p})>\hat{\phi}_{\mathrm{h}+\mathrm{m}-1}(\mathrm{p})$ on $[\mathrm{a}, \mathrm{b}]$. Also, using Lemma $2, \xi_{\mathrm{h}+1}(\mathrm{p})>0$ on $(\mathrm{a}, \mathrm{b})$ implies $\xi_{\mathrm{h}+\mathrm{m}-1}(\mathrm{p})>0$ on $(\mathrm{a}, \mathrm{b})$. The now familiar argument then yields $\hat{\succ}_{\hbar \mp \_}$strictly convex on $[a, b]$. It follows that

where is the period- $(\mathrm{h}+\mathrm{m}-1)$ price with the initial distribution and is the post-mps period- $(h+m-1)$ price. (The equality in (11) holds if there is no mps in period $h+m-1$.) Using the definition of $-\quad$ and the fact that ......., one concludes that -

Hence, by induction, $-\ldots \quad-\quad$ for $\mathrm{k}=1, \ldots, \mathrm{M}$, and in particular, $-\ldots \quad \ldots$

The prices for $\mathrm{j}=2, \ldots, \mathrm{h}$ remain iid with the initial distribution. (If $\mathrm{h}=1$, skip this step in the proof.) Given this and $-\ldots, \quad, \ldots$, Lemma 1 implies that,$- \quad-$ for $\mathrm{j}=2, \ldots, \mathrm{h}$.

To summarize, for any $\mathrm{j}=2, \ldots, \mathrm{h}+\mathrm{M},-\quad-$. Using $(6)$ and $(\ldots \ldots$, it follows that for $\mathrm{j}=1, \ldots, \mathrm{h}+\mathrm{M}-1, \quad$ on $[\mathrm{a}, \mathrm{b}]$. Finally, ... implies that for any such $\mathrm{j}$, for $\mathrm{A}>0$ and 
For the case of $\square$, the proof is strictly analogous to that for $\square$, the changes being that $\square$ is used, and that $\square$ for $\mathrm{j}=2, \ldots, \mathrm{h}+\mathrm{M}$. This completes the proof of the proposition.//

The discussion following Proposition 2, (as it relates to the second part of that proposition), carries over to Proposition 3. Part of the intuition that carries over takes the following form. If the consumer is worse off due to an increase in period- $(h+1)$ price uncertainty (when there are N-h-1 periods left in her life), she will be worse off with an increase in price uncertainty after period $h+1$, when there are fewer periods left in her life for adjustment to the increased uncertainty. Therefore the combination of increases in price uncertainty at and after period $h+1$ should make the consumer worse off if the increase in price uncertainty in period $h+1$ makes her worse off.

Symmetrically, if the consumer benefits from an increase in price uncertainty in period $h+1$, then she benefits from increases in price uncertainty in periods earlier than $h+1$, and from the combination of increases in price uncertainty in periods before and at period $h+1$. The counterpart of Proposition 3 is stated as follows with proof omitted.

Proposition 4. Suppose that there is a set of independent mps's, not necessarily the same, for two or more prices $\square$, where $\square$. Let $h+1$ denote the latest period in which there is an mps, where $h$ takes some value in $\{2, \ldots, N-1\}$. If $\square$ on $(a, b),{ }^{6}$ then for any $j=1, . ., h$, $\square$ for any $A>0$ and $\square$ (here, $\square$ is the initial, pre-mps value function and $\square$ the post-mps value function for period $j$ ). That is, for any such $j$ and corresponding realization $\square$, the consumer is better off.

\footnotetext{
${ }^{6}$ In the statement of Proposition 4, we define $\square$, i.e. If $\mathrm{h}+1=\mathrm{N}$, we must assume $\gamma<2$.
} 
Following upon the result in Proposition 3, another question comes to mind. Suppose initially a single mps in period $h+1$, for some , and suppose that this makes the consumer worse off than she would have been, in any given period $\mathrm{j}=1, \ldots, \mathrm{h}$, for any given associated realization . That is, for any $\mathrm{j}=1, \ldots, \mathrm{h}$, and corresponding realization

$\square$
$\square$ decreases. Is there a further decrease in these when one or more mps's are added for periods later than $\mathrm{h}+1$ ? It turns out that the condition

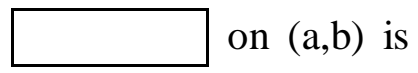
sufficient for an affirmative answer here.

Proposition 5. Suppose that initially there is a single mps in period $h+1$, for some and suppose that on $(a, b)$. Denote the resulting value functions $j=1, \ldots, h$. (From Proposition 2, we know that for $A>0$ and

Suppose that one or more further mps's are added for periods $h+i$, for some values of For the full configuration of mps's, denote the resulting value functions Then for $j=1, \ldots, h, \square$ for $A>0$ and $\square$.

Proof. As with the value functions in the statement of the proposition, denote values and functions resulting from the initial mps by a superscript "s" and those resulting from the full configuration of mps's by a superscript “ $t$ ".

The first part of the proof is parallel to the first part of the proof for Proposition 3. The execution -- establishing that $\square$, (for $\square$ ), and that $\square$, (for ), but for k only running over $2, \ldots, \mathrm{M}$-- is essentially unchanged and so is not repeated here. (The equalities $\longrightarrow, \mathrm{k}=2, \ldots, \mathrm{M}$, hold, because, as in Proposition 2, the (isolated) mps for $\square$ does not affect $\square$ for $\square$. However, again as in Proposition 2, $\square$.) Also, as for Proposition 3, the pattern of the proof for the case of $\square$ is strictly analogous to that for 
, so we attend only to the latter case. Finally, we omit many details of implications that are analogous to those in the proofs of Propositions 2 and 3.

Thus, take $\square$. It follows that on $[\mathrm{a}, \mathrm{b}]$. This implies that , where $\square$ is the price in period $h+1$ after the initial mps. From this last inequality, we have . This in turn implies that on [a,b]. We then have $+2$ for $\mathrm{A}>0$ and

If $\mathrm{h}>1$, consider periods $\mathrm{j}=1, \ldots, \mathrm{h}-1$. Given that Lemma 1 implies that $\square$ for any such $\mathrm{j}$. Then as before, $\square$ on $[\mathrm{a}, \mathrm{b}]$, implying that for $\mathrm{A}>0$ and $\square . / /$

There are immediate corollaries to Propositions 3-5, analogues to the corollary to Proposition 2. (There is the obvious difference that these corollaries involve conditions (9) and (10) separately. Also, for Proposition 4 , the indicated corollary holds only if the restriction $\mathrm{h}+1<\mathrm{N}$ is added. See footnote 6.) The significance of these corollaries is the same as for the earlier one: conditions (9) and (10) are independent of the timing of the increase in uncertainty being considered. In the interest of brevity, we omit explicit presentation of these additional results.

\section{3.b. Infinite horizon}

For the case of an infinite horizon, we denote the current period as period 1 with realization $\left(A_{1}, p_{1}\right)$. Initially, the prices for all future periods are iid with distribution function $F$ and support $[\mathrm{a}, \mathrm{b}]$, just as for the N-period case. Additionally, as for the N-period case, independence and the support $[\mathrm{a}, \mathrm{b}]$ are maintained when prices are not identically distributed. We introduce the subscript $\mathrm{k}=1,2, \ldots$ to index all periods.

The maximization here is strictly analogous to that for the N-period case. For the initial specification, we can drop the subscripts and obtain the resulting value function 
(12)

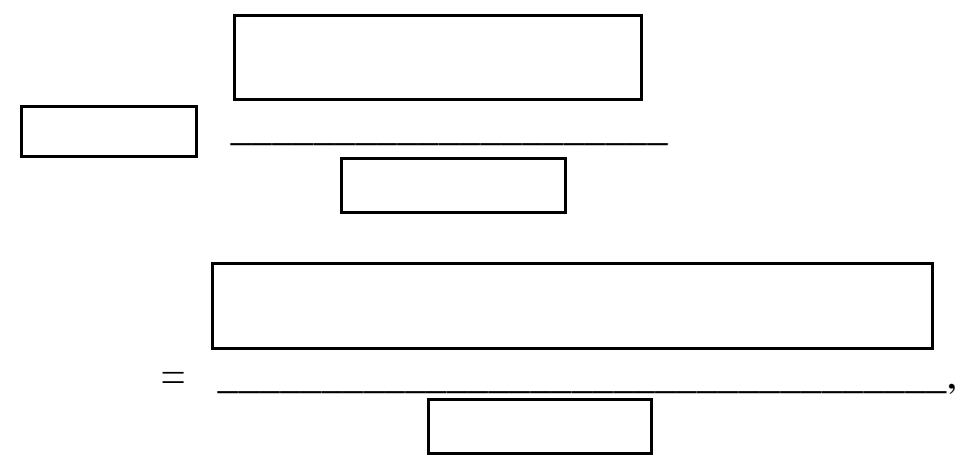

with $\square$ thus given by

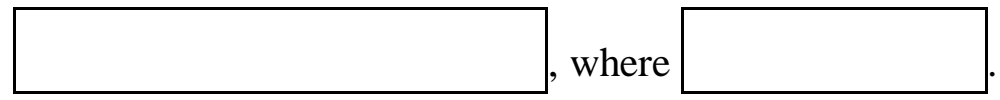

It is also immediate to derive the analogue to (7). If future prices are not identically distributed, or generally if we want to distinguish among periods when considering value functions or other variables, then (5)-(7), with the corresponding definition of $\square$, apply.

Using a suitable limiting argument, we can show that there exists a continuous function defined on $[a, b]$ satisfying (13). (It is clear from (13) that $\square$ is in fact differentiable in p.) From (13) we have

As there is no final period in the infinite-horizon case, we consider just the second and third types of increase in uncertainty distinguished in the finite-horizon case. That is, we consider the case in which an mps occurs in a single future period and the case in which (independent) mps's occur in multiple future periods, finite in number. ${ }^{7}$

Suppose that there is an mps in some single period $\mathrm{k}+1$, where Consider the function $\square$ defined by

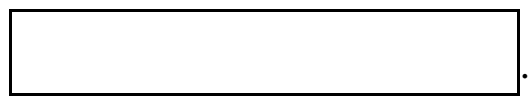

The following proposition for a single mps and an infinite horizon is identical to Proposition 2 except that (14) replaces (8).

\footnotetext{
${ }^{7}$ We conjecture that the restriction to a finite number of mps's is not necessary but have not proved this result.
} 
Proposition 6. If $\square$ on $(a, b)$, then for any $j=1, \ldots, k$ and corresponding realization increases. If $\square$ on $(a, b)$, then for any such $j, \square$ decreases.

The mps for $\square$ does not affect $\square$ and hence does not alter $\square$; $\square$ defined above and $\square$ on $[a, b]$, where $\square$ is defined in (13). As in the finite-horizon setting, the curvature properties of $\square$ are established using the sign of $\square$ on (a,b) and the size of $\square$. It is also immediate that Lemma 1 holds for $\mathrm{j}=1, \ldots, \mathrm{k}$. With these facts in hand, the proof of Proposition 6 is essentially identical to that for Proposition 2, and the intuitive discussion following Proposition 2, (except where that discussion inherently involves a finite number of periods), applies as well. Note that the function $\square$ is independent of the timing of the mps.

There is a corollary to Proposition 6 that is analogous to that to Proposition 2, the only change being that $\square$ replaces $\square$ (in condition (9)) and $\square$ (in condition (10)). Since $\square$ is already independent of the timing of the mps, the only force of the corollary is to replace the sufficient conditions in Proposition 6 by simpler conditions involving the values a and $b$.

We now take the case of an increase in uncertainty represented by a set of two or more (but finite in number) mps's in the context of an infinite horizon. For this case, in contrast to the finite horizon, we have results for increases and decreases in consumer well-being that involve the same timing of the mps's. Formally, this is because there is no role in the current context for anything like Lemma 2. Intuitively, the consumer always has infinitely many periods remaining and the initial condition against which the impact of increased price uncertainty is assessed is the same in every period. Hence, beginning with increased price uncertainty in some period $\mathrm{k}$ that is beneficial to the consumer, the increased uncertainty in period $\mathrm{k}$ combined with increased uncertainty in either earlier periods or later periods will still benefit the consumer. 
Proposition 7. Suppose that there is a finite set of independent mps's, not necessarily the same, for two or more prices $\square$. Let $h+1$ denote the earliest period in which there is an mps, and $h+M$ the last period in which there is an mps. Denote the post-mps value functions by $\square$. If $\square$ on $(a, b)$, then for any $j=1, \ldots, h+M-1, \square$ for $A>0$ and $\square$. If
$\square$ on $(a, b)$, then for any such $j, \square=0$ and $\square$

Proof. For the case of $\square$ on $(a, b)$, the proof is very similar to that for Proposition 3, the changes being that $\square$ everywhere replaces the $\square$ values and that in establishing $\square$, (for $\square$, and $\square$, (for $\square$, no analogue to Lemma 2 is required. Hence, we omit the proof for this case.

The case of $\square$ on $(a, b)$ has four subcases, (rather than the two for $\square$ on (a,b)), defined by $\square^{>1}\left(\square\right.$ ) and $\square^{>1} \square$. The proofs for these subcases are strictly parallel, with the obvious subcase-specific modifications; and these proofs are also very much parallel to those for $\square$ on $(a, b)$. So we restrict attention to $\square$ and $\square$, and provide merely a sketch of the proof.

Given the definition of $\mathrm{M}, \square$. We then have $\square$, and we know that $\square$ is strictly concave on $[\mathrm{a}, \mathrm{b}]$, so consequently $\square$.

An induction on the set $\mathrm{K}=\{1, \ldots, \mathrm{M}\}$ now establishes that $\square$ for $\square$. The induction is analogous to that in the proof of Proposition 3, with (i) $\square$ replacing the various $\square$ values, (ii) $\square$ replacing the functions $\square$, and with $\square$ strictly concave whereas the latter functions are strictly convex in Proposition 3, (iii) no use of a result such as Lemma 2, and (iv) reversal of inequalities where appropriate.

Focusing on the case of $h>1$, the prices for periods $j=2, \ldots, h$ remain iid with the initial distribution. It then follows from $\square$ that $\square$ for such j. Thus, $\square$ for $\mathrm{j}=2, \ldots, \mathrm{h}+\mathrm{M}$ 
and consequently, using

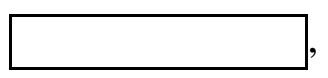
on $[a, b]$ for $\mathrm{j}=1, \ldots, \mathrm{h}+\mathrm{M}-1$. Hence, using $\square$, for all of these $h+M-1$ periods, $\square$ for $A>0$ and $\square . / /$

Finally, Proposition 8 below provides an answer to the symmetric version of the question addressed in Proposition 5: will a consumer, already made better off (worse off) due to a single mps in some period, be made still better off (still worse off) with the addition of further mps's in later periods? Because the elements of the proof of Proposition 8 can be easily provided on the basis of the proof of Proposition 5 and that of Proposition 7, we state the proposition without proof.

Proposition 8. Suppose that initially there is a single mps in period $h+1$, for some Denote the resulting value functions by $\square$. Suppose that one or more, but a finite number, of further mps's are added for periods $h+i$, with $\square$ taking values in some subset of $\{2,3, \ldots\}$. For the full configuration of mps's, denote the resulting value functions by $\square$. If $\square$ on $(a, b)$, then for $j=1, \ldots, h, \square$ for $A>0$ and $\square$. If $\square(a, b)$, then the inequalities are reversed.

\section{Numerical Examples}

In this section we present two numerical examples. The first involves a single mps, the second multiple mps's. In these examples we find combinations of the parameters $(\gamma, \rho)$ for which mps's in prices make the consumer worse off, using the condition that the function defined in (8), (in this section of the paper denoted simply $\square$ ) is positive (Propositions 2 and 3).

For simplicity, in the examples, the initial and post-mps distributions are discrete, rather than continuous as assumed in the use made of $\square$ in the proofs of Propositions 2 and 3. In the numerical examples we have examined, $\square$ being positive on the relevant discrete set of prices 
remains a sufficient condition for the consumer to be worse off. One can also think of approximating the discrete distributions arbitrarily closely with continuous distributions.

Example 1. N=3, $\square$. The relevant support is $\{.98,1,1.02\}$. The initial distribution assigns probability one to $\longrightarrow$. An mps is introduced in period 2 with probability of .5 assigned to $\square=.98$ and to $\square=1.02$.

Table 1: The combinations of parameters for which the mps in $\square$ makes the consumer worse off.

\begin{tabular}{|c|c|c|}
\hline$\square$ & $\begin{array}{c}\text { Consumer is worse off } \\
\text { with the mps in } \square \text { when }\end{array}$ & $\begin{array}{c}\text { Consumer is worse off } \\
\text { with the mps in } \square \text { when }\end{array}$ \\
\hline 2.5 & 1.968 & 0.005 \\
\hline 5.5 & 0.247 & 0.009 \\
\hline 7.5 & 0.143 & 0.011 \\
\hline
\end{tabular}

The table shows that, for instance, with risk aversion coefficient $\square$ set at 2.5 , the increase in uncertainty in the second period price makes the consumer worse off (in period 1) when the parameter $\square$ is either larger than 1.968 (i.e., with elasticity of intertemporal substitution (EIS) less than 0.508 ) or smaller than 0.005 (i.e., with EIS greater than 200). ${ }^{8}$ As the consumer becomes more risk averse ( $\square$ increases), the two threshold values of the parameter $\square$ become closer to each other. Column two shows that the threshold value of $\square$ decreases as $\square$ increases. An intuitive discussion related to this case was given following Proposition 2. In the present example $\square$ Hence by Proposition 2 and definition (8) of $\xi$ the increase in price uncertainty lowers consumer welfare if $\square$ is small enough or $\rho\left(\square^{-2}\right)$ is large enough. In the case at hand,

\footnotetext{
${ }^{8}$ The threshold values for $\square$ are defined for $\square$ in both examples. For each parameter pair, such as (2.5, 1.968 ) in the first example, the value of $\square$ is positive for $\square 0.98$ and 1.
} 
there is a tradeoff between $\square$ and $\rho$. As the consumer becomes more risk averse, she is more likely to be made worse off by the increase in price uncertainty unless she has a larger EIS (smaller $\square$ ).

An interesting feature of Table 1 is that the threshold value of $\rho$ is not necessarily decreasing in $\gamma$ and is not unique. The third column shows that when $\rho$ is close to 0 (EIS is large), then for a given level of risk aversion the consumer is more likely to be worse off with the increase in price uncertainty when she has a larger EIS. As was discussed following Proposition 2, this counter-intuitive result is due to the fact that when $\square$, if her EIS is large the consumer chooses to consume most of her resources early in her life. The "front-loading" consumption profile reduces the potential benefit of increased price uncertainty. For instance, consider the first row of Table 1 with $\square=2.5$. Our calculations show that when $\rho=1.968$ expected consumption in the last period of life is about $32.4 \%$ of the consumer's lifetime resources; in contrast when $\rho=0.005$ expected consumption in the last period of life is less than $\square$ of her lifetime resources. Because third period consumption is so low, even if $\square$ turns out to be low the consumer cannot take much advantage of the low price. As $\rho$ gets smaller, consumption becomes more frontloaded and the benefit of a potentially low price is further reduced. Given the degree of risk aversion the consumer becomes more likely to be worse off due to increased price uncertainty when her EIS is larger.

The third column also shows a positive relationship between $\square$ and the threshold value of $\rho$. When $\square$ becomes larger, the consumer leans toward less front-loading, and so, (connecting with the preceding argument), a given, large EIS contributes less to the likelihood that the consumer is made worse off by an increase in price uncertainty. Thus, the threshold value of the EIS is smaller (the value of $\square$ is larger).

It should be noted that our example shows that the EIS has to be very large for the unintuitive case to hold. The smallest EIS in the third column is about 100, which is much larger than what most empirical studies find. 
Example 2. $\square$, the support, and the initial distribution are as in Example 1. The same mps as in Example 1 is introduced in every period $j$ after the first period $(j=2,3, . . N)$. Several lengths of lifespan are considered: $N=3,5,7,10$.

Table 2: The combinations of parameters for which the set of multiple mps's makes the consumer worse off.

\begin{tabular}{|c|c|c|c|c|}
\hline$\square$ & $\begin{array}{c}\mathrm{N}=3, \text { consumer is } \\
\text { worse off if } \square\end{array}$ & $\begin{array}{c}\mathrm{N}=5, \text { consumer is } \\
\text { worse off if } \square\end{array}$ & $\begin{array}{c}\mathrm{N}=7, \text { consumer is } \\
\text { worse off if } \square\end{array}$ & $\begin{array}{c}\mathrm{N}=10, \text { consumer is } \\
\text { worse off if }\end{array}$ \\
\hline 2.5 & 1.968 & 5.999 & 10.029 & 15.074 \\
\hline 5.5 & .246 & .754 & 1.274 & 2.069 \\
\hline 7.5 & .142 & .446 & .748 & 1.212 \\
\hline
\end{tabular}

The second columns of Tables 1 and 2 both report the threshold values of $\rho$ for given values of $\gamma$; the former pertains to a single-period mps in second period price 2 , the latter to mps's in both second and third period prices. The results are in accord with Proposition 5: if the consumer is made worse off by an mps in price in a single period $\mathrm{k}$, then she is (even) worse off with the addition of mps's for prices after period $\mathrm{k}$. The results suggest that for small increases in price uncertainty the threshold values for the case of multiple mps's are quite similar to those for a single mps. Unlike the case studied in example 1 (where $\mathrm{N}=3$ ), for the cases $\mathrm{N}=5,7$, and 10 , is larger than 1, hence the "low-remaining-wealth" scenario does not appear and the threshold value of $\rho$ is decreasing in $\gamma$.

Table 2 provides a numerical assessment of the likelihood that an increase in price uncertainty reduces consumer welfare. For example, if $\mathrm{N}=7$ (that is, there are six years left in the consumer's life) and if the risk aversion coefficient $\gamma$ is 2.5 , then price uncertainty reduces consumer welfare if $\rho$ is larger than 10.029 (or the EIS is less than 0.1). As just noted above, for a given $\mathrm{N}$, the threshold value of $\square$ decreases as $\square$ increases. The intuition carries over from the single-mps case. As risk aversion increases, an increase in price uncertainty is more likely to make 
the consumer worse off unless the consumer is more willing to substitute consumption intertemporally, (that is, unless the EIS is higher ( $\square$ lower)).

Comparison of different columns of Table 2 shows that as $\mathrm{N}$ increases the threshold value of $\rho$ increases for a given value of $\gamma$. Intuitively: For a larger value of $\mathrm{N}$ there are more periods left after the realization of a given period's price, for instance, the period 2 price. The agent has more time to respond to the observed price. For the consumer to be worse off given the level of risk aversion, the EIS must be lower ( $\square$ must be larger).

\section{Empirical Literature on the Values of Parameters $\rho$ and $\gamma$}

The foregoing development focuses on the role of risk aversion, measured by the parameter $\square$, and intertemporal substitution, measured by the inverse of the structurally distinct parameter $\square$, in determining the impact of price uncertainty on consumer welfare. It is therefore of interest to briefly review the findings of the empirical literature regarding these parameters.

Studies that focus on elements of asset return data find that $\square$ has to be large. The simulations by Kocherlakota (1990a), Cecchetti et al (1992), and Kandel and Stambaugh (1990), employing a standard expected-utility representation of preferences, conclude that $\square$ should be around 13.7, 29, and 55 respectively, in order to explain the observed equity premium. Weil (1989) derives asset-pricing implications of a model embodying the preference structure used in this paper. With $\square$ set at 0.95 , he finds that to explain both the observed equity-premium and the risk-free rate in the U.S. economy the risk aversion coefficient $\gamma$ should be about 45 and the elasticity of intertemporal substitution $1 / \rho$ should be about 0.1 (i.e., $\rho$ should be about 10 ).

Estimation of the parameters $\square$ and $\square$ is a common exercise in the literature of consumption-based asset pricing theory. Much of the earlier empirical work involves tests of consumption-based asset-pricing models using the state-separable utility function, , with $\square$ serving the dual roles of coefficient of relative risk aversion and 
the inverse of the elasticity of intertemporal substitution. Estimation using the Generalized Method of Moments (GMM) often produces low estimates for $\square$. For example, Mankiw et al (1985) find $\square$ to be close to 0.3 and Hansen and Singleton (1982) find $\square$ to be close to 0.8. ${ }^{9}$ Hall (1988) argues that the estimated parameter, $\square$, of the state-separable utility function actually measures the inverse of the elasticity of intertemporal substitution $\square$. He concludes that empirical evidence supports the view that $1 / \square$ is quite small, (in the neighborhood of 0.1 ). Weil (1990) points out that, within the context of the preference structure of this paper, Hall's interpretation is valid if asset returns are lognormal. Kocherlakota (1990b) argues that consumption growth and asset returns cannot be jointly lognormal if consumer preferences have a non-expected utility representation. He argues that Hall's estimated parameter $\square$ likely reflects risk aversion. Some recent studies employ preference structures that explicitly separate the parameters $\square$ and $\square$. Epstein and Zin (1991) find that $1 / \square$ is about 0.2 to 0.9 and $\square$ is close to 1 . However, Jorion and Giovannini (1993) find that $\square$ and $\square$ cannot be precisely estimated. Their estimates of $\square$ and $\square$ vary considerably, with estimates for $\square$ as large as 13, and estimates for $\square$ as large as 12 , depending on whether the estimation method is maximum likelihood or GMM, and for the latter case, the instruments used for estimation. ${ }^{10}$

In summary, in this literature there is considerable disagreement regarding estimates of the coefficient of relative risk aversion and the elasticity of intertemporal substitution. What can be said, from the perspective of the current paper, is that many of the estimates are consistent with increases in intertemporal price uncertainty being welfare reducing.

\section{Conclusion}

\footnotetext{
${ }^{9}$ Dunn and Singleton (1986), Eichenbaum, Hansen, and Singleton (1988), Eichenbaum and Hansen (1990), and Ogaki and Reinhart (1998) show that the estimated EIS depends on, in addition to consumption of nondurables, whether and how consumption of leisure and durable goods are introduced into the utility function.

${ }^{10}$ Some of Jorion and Giovannini's estimates for $\rho$ and $\gamma$ are even negative.
} 
In this paper we examine how intertemporal price uncertainty affects consumer welfare. We employ a preference structure in which the coefficient of relative risk aversion and the elasticity of intertemporal substitution (EIS) are parametrically independent. This allows us to highlight the distinct roles they play in determining the impact of increased intertemporal price uncertainty on consumer welfare.

The coefficient of risk aversion $(\square)$ being larger than 2 is a necessary condition for the consumer to suffer from increases in intertemporal price uncertainty. No comparable necessary condition exists for the EIS $(\square$. Given that $\square$ is greater than 2 , for an arbitrary pair $\square$ and $\rho$, younger consumers are less likely to be worse off due to a given increase in price uncertainty than are older consumers. Under empirically plausible circumstances, for a given value of $\square$ if $\rho$ is larger than a corresponding threshold value, then the consumer is worse off with an increase in price uncertainty. In other words, for a given degree of risk aversion, increased price uncertainty reduces consumer welfare if the EIS is sufficiently low. For higher $\square$ the threshold value of $\square$ is lower; if an increase in the degree of risk aversion is not offset by a large enough increase in the EIS, the consumer suffers from an increase in price uncertainty. However, if the EIS is very large, the relationship can change: as the degree of risk aversion increases, it is possible that an increase in the EIS makes it more likely that increased price uncertainty reduces consumer welfare.

As is indicated above, in the empirical literature the range of estimates for $\square$ and the EIS is broad. However, for much of this range, (specifically, moderate to large coefficient of risk aversion and small EIS), the results of this paper suggest that increases in intertemporal price uncertainty are likely to reduce the welfare of consumers. 


\section{References}

Anderson, Evan W., Las P. Hansen, and Thomas J. Sargent (2000), "Robustness, Detection, and the Price of Risk," Working paper, University of Chicago.

Baye, Michael, R. (1985), "A Note on Price Stability and Consumers' Welfare," Econometrica, vol.53, January, 213-16.

Cecchetti, Stephen G., Pok-sang Lam, and Nelson C. Mark (1993), "The Equity Premium and the

Risk Free Rates: Matching the Moments," Journal of Monetary Economics, vol.

February, 21-45.

Dunn, Kenneth B. and Singleton, Kenneth J. (1986), "Modeling the Term Structure of Interest Rates Under Non-Separable Utility and Durability of Goods," Journal of Financial Economics, vol.17, September, 27-55.

Eichenbaum, Martin S. and Hansen, Lars P. (1990), "Estimating Models With Intertemporal Substitution Using Aggregate Time Series Data," Journal of Business and Economic Statistics, vol. 8, January, 53-69.

Eichenbaum, Martin S., Hansen, Lars P. and Singleton, Kenneth J. (1988), "A Time Series Analysis of Representative Agent Models of Consumption and Leisure Choice Under Uncertainty," Quarterly Journal of Economics, vol. CIII, February, 51-78.

Epstein Larry G. and Stanley E. Zin (1989), " Substitution, Risk Aversion, and the Temporal Behavior of Consumption and Asset Returns: A Theoretical Framework," Econometrica, vol. 57, July, 937-69.

Epstein Larry G. and Stanley E. Zin (1991), "Substitution, Risk Aversion, and the Temporal Behavior of Consumption and Asset Returns," Journal of Political Economy, vol.99, 263-86.

Giovannini, Alberto and Philippe Weil (1989), "Risk Aversion and Intertemporal Substitution in the Capital Asset Pricing Model," NBER working paper no. 2824.

Hall, Robert E. (1988), "Intertemporal Substitution in Consumption," Journal of Political Economy, vol. 96, April, 339-57. 
Hansen, Lars Peter and Kenneth Singleton (1982), "Generalized Instrumental Variables Estimation of Nonlinear Rational Expectation Models," Econometrica, vol. 50, September, 1269-86.

Jorion, Philippe and Alberto Giovannini (1993), "Time Series Tests of a Non-Expected-Utility Model of Asset Pricing," European Economic Review, vol. 37, 1083-1100.

Kandel, Shmuel, and Robert F. Stambaugh (1990), "Expectations and Volatility of Consumption and Asset Returns," Review of Financial Studies, 207-32.

Kocherlakota, Narayana R. (1990a), "On Tests of Representative Consumer Asset Pricing Models," Journal of Monetary Economics, vol.26, October, 285-304.

Kocherlakota (1990b), "Disentangling the Coefficient of Relative Risk Aversion from the Elasticity of Intertemporal Substitution: An Irrelevance Result," Journal of Finance, vol. XLV, March, 175-90.

Maenhout, Pascal J. (1999), "Robust Portfolio Rules and Asset Pricing," Working paper, Harvard University.

Mankiw, Gregory N., Julio J. Rotemberg, and Lawrence H. Summers (1985), "Intertemporal Substitution in Macroeconomics," Quarterly Journal of Economics, vol. C, 225-51.

Ogaki, Masao and Carmen M. Reinhart (1998), "Measuring Intertemporal Substitution: The Role of Durables," Journal of Political Economy, vol.106, 1078-98.

Rothschild, Michael and Joseph E. Stiglitz (1970), “Increasing Risk: I. A Definition,” Journal of Economic Theory, vol.2, 225-43.

Turnovsky, Stephen J., Haim Shalit, and Andrew Schmitz (1980), "Consumer Surplus, Price Instability, and Consumer Welfare," Econometrica, vol.48, January, 135-52.

Waugh, Frederick V. (1944), "Does the Consumer Benefit From Price Instability?" Quarterly Journal of Economics, August, 602-14.

Weil, Philippe (1989), "The Equity Premium Puzzle and the Risk-Free Rate Puzzle," Journal of Monetary Economics, vol.24, 401-21.

Weil, Philippe (1990), "Nonexpected Utility in Macroeconomics," Quarterly Journal of Economics, vol. CV, February, 29-42. 